investigating deployment in time. One does not wholly escape the trendy titles and jargon phrases that bestrew the sociobiological field; for instance, consider PMP, which is the Pontryagin Maximum Principle ( $M r$ P being a Soviet rocket engineer). But on the whole the contributions are readable without too much irritation.

Throughout emphasis is laid on the theoretical development of quantitative predictions which can be tested, and are tested, by observation and experiment both in field and laboratory. Sometimes, as in much science, there is a flavour of proving the obvious. Sometimes one has the feeling of reading a modern Aesop's fable. But in general we feel the refreshing current of uncommitted thought that is throwing much light on the fascinating problems of how and why animals behave.

G.V.T. MATTHEWS

\title{
Malayan Forest Primates, edited by David Chivers. Plenum Press, $\$ 42.50$.
}

This is a remarkable book. It summarises 10 years' work on the siamang and lar gibbons, as well as studies of dusky and banded leaf monkeys, and long-tailed macaques, their competitors, and their forest in the Krau Reserve of Malaysia. The style is academic, written for other primatologists, with quantitative analysis where possible - primatology has come of age. It takes a study of this precision and magnitude to deal with a rainforest whose emergent trees tower to 80 metres, and where a primate may have access to 400 species of large tree (over $50 \mathrm{~cm}$ girth at breast height) without counting the hundreds more smaller trees and epiphytes. A gibbon's generation time is nearly a decade, so it also takes a study of this length to show patterns of group change.

Much of the data has been published before. The synthesis has not. Readers interested in cross-species or cross-forest comparison will turn to this volume for information, as will those who want quantitative background to efforts for forest primate conservation. One could cite many different articles - Curtin's deciphering of the unorthodox leaf-monkeys, the MacKinnons' direct comparison of different species at the same place and time, Fleagle's elegant analysis of locomotion. Perhaps the aspect which pleased me most was that Chivers and Raemakers, in their two summary articles dealt with both individuals and statistics. Where they have enough information for mathematical analysis, as in the interrelations of climate, tree phenology, and primate ranging, they have written straight ecology. Where individual lives are important, we are told that too. It is a healthy sign for primatology that both approaches have their place, and that his book of quantitative primate ecology is dedicated to the memory of the siamang, Murgatroyd, 'paragon of monogamous fidelity and fatherhood'.

ALISON JOLLY

\section{Ibexes in an African Environment, by B. Nievergelt. Springer-Verlag, $\$ 40.50$.}

This unusual monograph is centred on the biology of the walia ibex but also deals in detail with the biology of the partially sympatric gelada baboon and klipspringer. In addition there are thumbnail descriptions of the niches within the Ethiopian Simien Mountain ecosystem occupied by a further fourteen mammals, including man. Combined with the description of the vegetation at different altitudes, the work provides the reader with a complex picture of the way the mammals play their part in Simien ecology, and shows a depth of analysis not easily attained in studies of rare species such as the walia, whose low numbers and inaccessible habitat makes data gathering difficult. Academic biologists shun potentially important studies of rare species just because of these difficulties, so it is pleasing to see a work which makes an important contribution to the theory and practice of the accurate evaluation of sparse data typical of studies on rare species. The centre piece is an analysis of the preferred 
habitat of the walia, gelada and klipspringer and a description of their ecological separation.

The book is slightly marred by overcomplex presentation of the data and by a confused use of the terms 'factor' and 'parameter' in chapter 8 and throughout. Nevertheless this is essential reading for wildlife biologists and ecologists, and the non-mathematical descriptive sections are of potential interest to a wide public, especially those interested in the flora and fauna of Africa.

PAUL MUNTON

Rare and Endangered Plants of New Zealand, by D.R. Given. A.H. \& A.W. Reed, $\$ 22.95$.

Many books have been written about rare and endangered animals, particularly birds and mammals, with the aim of stimulating public interest and concern. The plight of plants has been less well publicised although there have been several recent red data compilations at an international and national level.

David Given successfully brings forward another approach to our understanding of the subject. He points out that plant species in New Zealand (as elsewhere) have evolved and colonised without man's assistance and are an irreplaceable part of New Zealand's heritage. Whether they become a vanishing heritage or survive and prosper is, however, in man's hands. The challenge is great, for it is estimated that one in ten of New Zealand's native plant species can be described as at risk and simple human ignorance is often responsible. Given has examined broad habitats describing threatened plants in coastal areas, open and rocky places, wetlands, forest and scrub, islands and alpine regions. The effectiveness of this approach obviously rests on a detailed and comprehensive understanding of the floristics and ecology of the vegetation, and David Given has a familiarity with the New Zealand vegetation which must be the envy of many. He has been able to describe the occurrence and distribution of threatened plants in a habitat context and clearly defines the threats and how they might be ameliorated.

One problem facing workers anxious to stimulate public interest is the extent to which detailed information on localities is provided. It is important to encourage people to find new occurrences but there are all too many examples of unscrupulous collectors using such information to the decimation of the plant, and Given has adopted the policy of not providing detailed site records; distribution is given only in general terms.

The book contains valuable chapters on the concepts of rarity and strategies for survival. The final chapter 'The Personal Challenge' presents the author's own philosophy on conservation, and clearly reveals that David Given is not only a leading authority on rare and threatened New Zealand plants but a dedicated conservationist.

JOHN LEIGH

\section{The Biological Aspects of Rare Plant Conservation, edited by Hugh Synge. Wiley, $£ 30.00$.}

These proceedings of an international conference, held at Cambridge in July 1980, have been brought through to publication with commendable speed. It grew out of the concern of taxonomists at the increasing speed of extinction of rare species, and included ecologists, phytosociologists and practising conservationists.

The first quarter of the text is a survey and assessment of rare and threatened species, with contributions from North America, the USSR, India, Australia, New Zealand and Europe. A shorter section on the crucial topic of Tropical Forests is followed by a series of papers on the problems of what really constitutes rarity and how rare plant populations can be monitored, and a further ten papers on ecological studies of rare 